\section{Conditioned adaptation to prismatic displacement with a tone as the conditional stimulus*}

\author{
JEROME H. KRAVITZ \\ Howard University, Washington, D.C. 20001 \\ and \\ FRED YAFFE
}

Eye Research Foundation of Bethesda, Bethesda, Maryland 20014

Adaptation to prismatic displacement was conditioned to a tone in $72 \mathrm{~min}$ of training by employing Taylor's alternation training technique. The alternation consisted of two training conditions. In one, $S$ was exposed to the prism and tone; in the other, $\mathbf{S}$ was exposed to neither. After training, the pointing to a visual target test measured more aftereffects of adaptation when the tone was present than when it was absent. Conditioning was obtained in two testing situations: (1) with the training goggles still worn by $S$, and (2) with the goggles removed.

When an optical device tilts, distorts, or displaces the viewer's visual field, it initially causes errors in localization responses (effect). These errors decrease in magnitude (adaptation effect) after some appropriate practice by $S$. The adaptation effect measures are in turn taken to reflect an underlying psychological compensation (adaptation) to the optical disarrangement. Responses then made with the removal of the device exhibit an error in the direction opposite to the effect (aftereffect). For some time, aftereffects were assumed to be conservative estimates of adaptation effects and as an equally valid indicator of adaptation because, in the early studies which measured both, the magnitude of the former so nearly agreed with the magnitude of the latter (Rock, 1966). Conditioned adaptation (CA) studies, however, have indicated that this equality need not always hold.

CA studies usually have two major parts: a training period and testing periods. The training period is designed to produce an association between the adaptation and a previously neutral stimulus. This is achieved by employing two alternating training conditions, one with normal vision and the other with vision modified by the optical device, and also by the systematic covariation with the training exposure conditions of other afferent processes, specifically the absence and presence of the neutral stimulus. CA effects are taken to be present when in the testing period the adaptation effects or aftereffects obtained with the neutral

*This study was supported by National Institute of Neurological Disease and Stroke Grant NB 08696-01. stimulus present are greater than those obtained with it absent.

Taylor (1962) produced differential conditioned adaptations by systematically covarying the training exposure conditions with the sensations produced by wearing spectacles that housed the optical refined the Taylor alternation training technique and associated the adaptation to prismatic displacement to the wearing of goggles in $240 \mathrm{~min}$ of training. This study replicated Taylor's findings-namely, that there were larger adaptation effects with the goggles in place than aftereffects with them removed. It also demonstrated that a ftereffects obtained while wearing the goggles without a prism were larger than those obtained without goggles.

The present study addresses itself to an important issue regarding the conditional stimulus (CS) employed in previous studies. For, although goggles and spectacles qualify as neutral stimuli, two objections arise concerning their use.

First, they are poor variables: they may not be easily varied beyond their mere present or absence, and they exposed to the optical device.

Second, goggles produce some CA effects which are less than definitive. That is, due to their intimate and necessary connection with the optical device, they leave open the possibility that results obtained with the "pointing to a visual target test" are due to "conscious correction" by $S$.

Notwithstanding verbal testimony by $S$ to the contrary, it would still be preferable to employ a CS which did not have such a direct and necessary connection with the optical device. Thus, these shortcomings would be device. Recently, Kravitz (1972) must always be present when the $S$ is rectified if a tone could be employed as the CS.

\section{EXPERIMENT}

The present study attempted to condition adaptation to prismatic displacement to a tone.It employed Taylor's alternation technique of training, which involved exposing $S$ to two alternating training conditions. In one condition, the presenation of prismatically altered viewing (P) was paired with the hearing of a tone $(T)$. In the other condition, unaltered viewing $(\bar{P})$ was paired with the absence of the tone (T). This alternation could effect a pair of associations, one between the adaptation and the tone, and the other between normal functioning and silence-in other words, possibly producing differential conditioned adaptation. Were these associations effected, then, during testing, the presentation of the tone should elicit larger aftereffects of adaptation than those obtained without the tone.

The experiment employed two groups: an experimental group (E) and a control group (C). E received 12 alter, sations for a total training time of $72 \mathrm{~min}$, whereas $\mathrm{C}$ received $36 \mathrm{~min}$ of continuous (PT) training.

\section{Subjects}

The 30 udnergraduates solicited by advertisement in the University of Maryland's school newspaper to serve as paid voluntary Ss were divided equally between Groups $\mathbf{E}$ and $\mathbf{C}$.

\section{Apparatus}

The displacement of the visual field was produced by a Hughes rotary prism mounted on the right frame of a pair of welder's goggles. A small high-speed reversible electric motor attached to the prism's gear changed the displacement in effect from 0 to 20 diopters base left. 1 The motor was controlled by a relay complex, which was in turn controlled by the output from one channel of a two-channel Sony cassette tape recorder (Model TC 124). Recorded simultaneously on both channels of the cassette's tape was a 1,000-Hz tone. The $\mathrm{E}$ recording consisted of 12 alternations of $3 \mathrm{~min}$ of tone (T) and $3 \mathrm{~min}$ of silence $(\bar{T})$, for a total of $72 \mathrm{~min}$. The $\mathrm{C}$ recording consisted of $36 \mathrm{~min}$ of continuous tone. The output from the cassette's second channel went to a stereophonic ear plug system worn by $S$.

A long umbilical wire from the cassette and the relay allowed $S$ considerable freedom of movement while wearing the goggles and ear plugs. The line from the relay to the motor was interrupted by a switch which, when closed, allowed the prism 


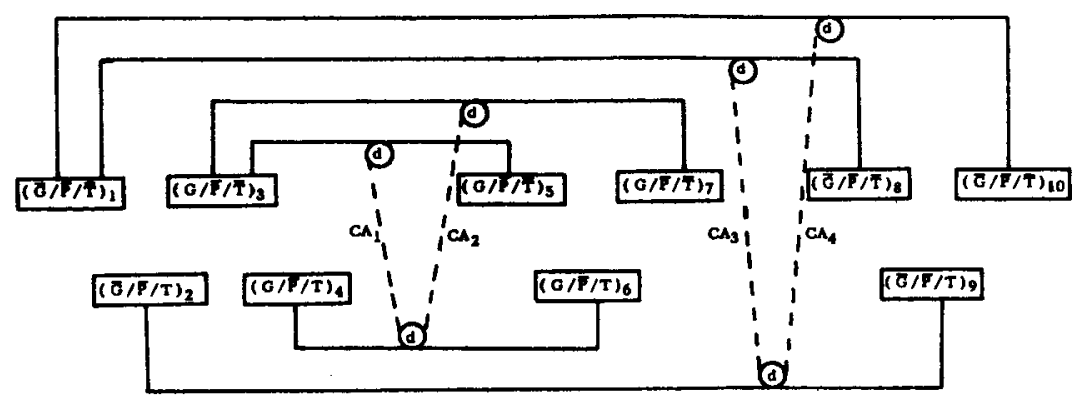

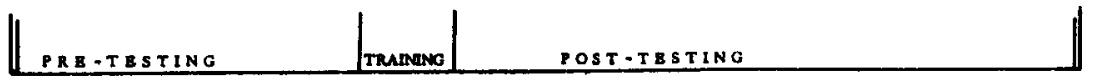

Fig. 1. Test condition sequence of the experimental (E) and control group (C). The solid lines represent differences between pre- and posttraining test conditions which result in the measurement of aftereffects (d) of adaptation. Dashed lines connecting (d) symbols represent differences between $T$ and $\mathbf{T}$ effects and result in the measurement of conditioned adaptation effects $\left(C_{1}\right.$, etc.).

to remain at a 0 diopter position while the tone was in effect.

The testing apparatus was a 60-in.-long $\times$ 26-in.-deep vertically adjustable horizontal platform. When raised to shoulder level, it allowed $S$ to easily extend his arm underneath it. On the platform's near edge, a biteboard apparatus was fixed. On the far side of the platform was a 40-in.-wide $x$ 30-in.-high panel perpendicular to S's line of regard. The pointing test target was a vertically oriented black bar, $21 / 4 \times 1 / 4$ in. It was visible in three different positions: $6 \mathrm{deg}$ to the left, straight ahead, and $6 \mathrm{deg}$ to the right of $\mathrm{S}$, through an eye-level 30-in.-long horizontal slit in the rear panel. The rear panel and the remainder of the apparatus were painted flat white. A meter stick permitted determination by $E$ of $S$ 's pointing responses. At all times, an eye patch occluded S's left eye.

\section{Responses}

The experiment employed two different manual localization tests to measure the effects of training. Both required that $S$ stand biting the biteboard, extending his right arm under the platform and pointing with his right index finger. At the testing apparatus, $S$ had his eyes closed at all times, except when making a pointing response. Each pointing response had $S$ open his eyes and point under the platform at the apparent location of the target. The testing platform prevented any visual feedback regarding the accuracy of his response. The pointing test (Ptg) measure was the mean of six pointing responses, two for each target position (Wallach, Kravitz, \& Lindauer, 1963). The straight-ahead test (SA) measure was the mean of two responses in which $S$ pointed, with eyes closed, "straight ahead" (Harris, 1963).

\section{Test Conditions}

These tests were performed in four testing situations. These testing situations were sequentially arranged to produce a total of 10 test conditions. The situations were: (1) (GPT) S wore goggles (G), was exposed to a 0 diopter displacement, i.e., normal viewing $(\bar{P})$, and heard the

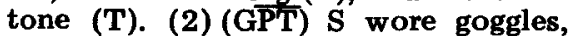
had normal viewing $(\overline{\mathrm{P}})$, and the tone was absent (T). (3) (GPT) $S$ wore no goggles $(\overline{\mathbf{G}})$, had normal viewing, and heard the tone. (4) (GPT) $S$ wore no goggles, had normal viewing, and the tone was absent.

\section{Experimental Design}

Both groups participated in the same three successive segments of the experiment: pretesting, training, and posttesting. Figure 1 depicts the manner in which the four test situations were distributed among the two testing segments of the experiment, resulting in a total of 10 separate testing conditions. The subscripted numbers affixed to each test condition indicate its order of occurrence. Each $S$ went through the following sequence: (1) pretesting, which entailed four test conditions, $(\overline{\mathrm{GPT}})_{1},(\overline{\mathrm{GPT}})_{2},(\overline{\mathrm{GPT}})_{3}$, and $(\mathrm{GPT})_{4}$; (2) training; and (3) posttesting, which entailed six test conditions, $(\mathrm{G} \overline{\mathrm{PT}})_{5}$, $(\mathrm{GPT})_{6},(\mathrm{GPT})_{7},(\overline{\mathrm{GPT}})_{8},(\overline{\mathrm{GPT}})_{9}$, and $(\mathrm{GPT})_{1}$.

The first-order effects of training (i.e., the aftereffects) were determined by obtaining the difference between the pre- and posttraining measures of a given test in a given test condition. These differences are represented in Fig. 1 by solid lines connecting the pretest conditions to the posttest conditions. Since these differences are between $\overline{\mathbf{P}}$ test conditions, they measure the aftereffects of adaptation. Thus, we obtain from the testing six aftereffect measures from each to (i.e., Ptg and SA). The symbol ( appended to each solid line, represer the resulting aftereffect measure.

Measurements of condition adaptations (CA) are, howev second-order effects. That is, the measurement results from obtaini the difference between two kinds aftereffect measures: those obtain (1) when the tone is present (T) al (2) when the tone is absent (T).

Thus, it was expected that $t$ $(\mathrm{GPT})_{6}$ aftereffects would be great than the (GPT), and (GPT aftereffects to the extent that $t$ adaptation had become conditional associated to the tone. The differen between the $T$ aftereffect and each the $\bar{T}$ aftereffects (indicated in Fig. by the dashed lines, $\mathrm{CA}_{1}$ and $\mathrm{CA}$ connecting the first three $d$ symbo will be considered the measures of $t$ conditioned adaptation (CA Similarly, even if the goggles a removed during testing $(\bar{G})$ conditio: $(8,9$, and 10), the $T$ aftereffec should be greater than the aftereffects to the extent that $t$ adaptation had become conditional associated to the tone. The differen between these effects (indicated Fig. 1 by the dashed lines $\mathrm{CA}_{3}$ ar $\mathrm{CA}_{4}$ which connect the last three symbols) will also be consider measures of conditioned adaptatio

\section{Training Procedure}

The experimental groups (E). TH group received alternation traini designed to produce different conditioned adaptation to the hearis of a tone. The total training time each $S$ was $72 \mathrm{~min}$. Of this tim 36 min were spent wearing the goggl with the prismatic displacement effect and hearing the tone (GPT 36 min with the goggles still in pla but with normal nondisplaced viewi and the tone absent (GPT). The (GP time was divided into 12 separa 3-min occasions which alternated wi the 12 separate $3-\mathrm{min}$ (GP' occasions. Training began with (GPT) exposure and ended with (GPT) exposure.

During training, $S$ performed number of tasks, each designed produce rapid adaptation. The tas were: sitting and looking at I "passively resting" right arm while was stimulated by vibration (Kravitz Wallach, 1966), throwing a ball at target, putting golf balls, and $t$ throwing and recovery of das (Kravitz, 1972). S could see the resu of his performance. The $P$ and $\bar{P}$ errc were approximately equal in size $b$ on opposite sides of the targets. The tasks were scheduled so that the sar task was performed in both segmer of a given alternation.

The control group (C). The $\mathrm{C}$ grol 
was included to determine whether $\mathbf{S}$ would form an association between the tone and adaptation if he were simply exposed to their simultaneous and continuous presentation over an extended period of training. To determine this, $C$ received a single continuous 36-min (GPT) training exposure. During this time, $S$ performed the same training tasks as were employed in $\mathrm{E}$. Moreover, since the total (GPT) training time of $E$ and $C$ were the same, we can also determine whether alternation training or continuous training results in more of the conditional association.

\section{RESULTS AND DISCUSSION}

Table 1 presents a summary of the aftereffects obtained by the Ptg and SA tests. Each figure is the mean difference of pre- and posttraining measurements and is listed by its postraining test condition.

The $\mathbf{C}$ group produced aftereffects which were relatively large and highly significant for both the Ptg and SA tests (Columns 3 and 4 ) under all testing conditions. The $\mathbf{E}$ aftereffects on the Ptg test were significant in all aftereffects were somewhat less consistent. Of the $G$ test conditions, only the sixth test condition measured a significant SA effect, whereas a significant SA effect was obtained in each of the $\bar{G}$ test conditions.

However, our major concern is whether CA effects were obtained. That is, (1) are the (GT) aftereffects larger than the (GT) aftereffects? and (2) were the (GT) aftereffects larger than their corresponding (GT) aftereffects.

Table 2 presents a summary of the mean conditioned adaptation effects obtained on the Ptg test and the SA test. The "with goggles" $\mathrm{CA}_{1}$ and $\mathrm{CA}_{2}$

Table 2

Mean Conditioned Adaptation Measures in Degrees

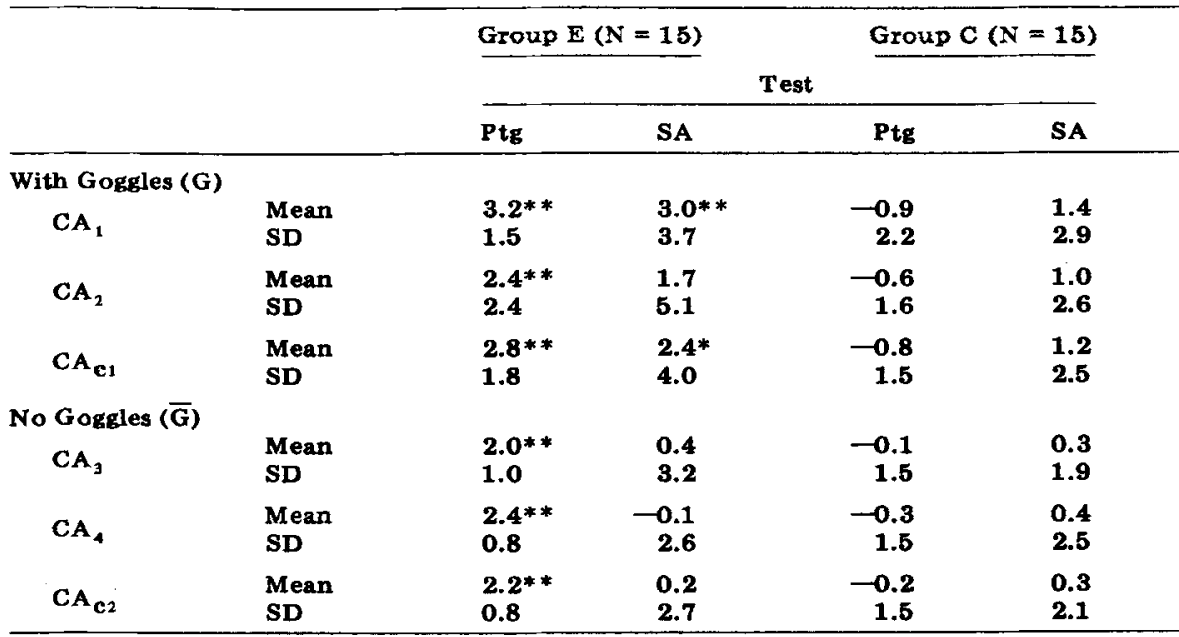

Note- + signifies $T$ effects $>\bar{T}$ effects. - signifies $T$ effects $<\bar{T}$ effects. **, * denote deviations significantly different from zero; $p<.01$ and $p<.05$, respectively, with two-tailed tests. testing conditions. The E SA

figures represent the mean differences between the aftereffects $(\mathrm{GPT})_{6}$ and the aftereffects $(G \overline{P T})_{5}$ and $(G \bar{T})_{7}$ respectively. $\mathrm{CA}_{\mathrm{Cl}_{1}}$ is the mean of the $\mathrm{CA}_{1}$ and $\mathrm{CA}_{2}$ effects.

The "no goggles" $\mathrm{CA}_{3}$ and $\mathrm{CA}_{4}$ figures represent the mean differences between the aftereffects ( $\overline{G P T})_{2}$ and the aftereffects $(\overline{\mathrm{GPT}})_{8}$ and $(\overline{\mathrm{GPT}})_{10}$, respectively. $\mathrm{CA}_{\mathrm{c}_{2}}$ is the mean of the $\mathrm{CA}_{3}$ and $\mathrm{CA}_{4}$ effects.

The "with goggles" Ptg CA $\mathrm{CA}_{1}, \mathrm{CA}_{2}$, and $\mathrm{CA}_{\mathrm{C}_{1}}$ effects obtained from the control group, $\mathbf{C}$, were negative (i.e., the $\overline{\mathrm{T}}$ aftereffects were greater than the $T$ aftereffects) and not significant. However, the "with goggies" Ptg CA effects obtained from $\mathrm{E}$ were all highly significant. $A$ test comparison revealed that the $E$ Ptg $\mathrm{CA}_{c_{1}}$ effect was significantly larger (3.6 deg) than that of $\mathrm{C}(\mathrm{t}=5.473, \mathrm{df}=28, \mathrm{p}<.01)$.

Table 1

Mean Aftereffects $(\bar{P})$ in Degrees Listed by Postraining Test Condition

\begin{tabular}{|c|c|c|c|c|c|}
\hline & & \multicolumn{2}{|c|}{ Group E $(N=15)$} & \multicolumn{2}{|c|}{ Group $C(N=15)$} \\
\hline \multicolumn{2}{|c|}{ Test Conditions } & Ptg & $\mathbf{S A}$ & Ptg & SA \\
\hline$(\mathrm{GPT})_{s}$ & $\begin{array}{l}\text { Mean } \\
\text { SD }\end{array}$ & $\begin{array}{l}2.2^{*} \\
3.8\end{array}$ & $\begin{array}{l}0.5 \\
4.0\end{array}$ & $\begin{array}{l}7.9^{* *} \\
\mathbf{3 . 3}\end{array}$ & $\begin{array}{l}4.6 * * \\
3.6\end{array}$ \\
\hline$(\mathrm{GPT})_{6}$ & $\begin{array}{l}\text { Mean } \\
\text { SD }\end{array}$ & $\begin{array}{l}5.4 * * \\
3.0\end{array}$ & $\begin{array}{l}3.5 * * \\
4.0\end{array}$ & $\begin{array}{l}7.0^{* *} \\
2.6\end{array}$ & $\begin{array}{l}6.0^{* *} \\
3.1\end{array}$ \\
\hline$(\mathrm{G} \overline{\mathrm{PT}})_{7}$ & $\begin{array}{l}\text { Mean } \\
\text { SD }\end{array}$ & $\begin{array}{l}3.0^{* *} \\
3.2\end{array}$ & $\begin{array}{l}1.8 \\
3.4\end{array}$ & $\begin{array}{l}7.6 * * \\
2.6\end{array}$ & $\begin{array}{l}5.0^{* *} \\
2.9\end{array}$ \\
\hline$(\overline{\mathrm{GPT}})_{8}$ & $\begin{array}{l}\text { Mean } \\
\text { SD }\end{array}$ & $\begin{array}{l}2.0^{* *} \\
1.8\end{array}$ & $\begin{array}{l}3.2^{*} \\
4.1\end{array}$ & $\begin{array}{l}\mathbf{5 . 8 * *} \\
\mathbf{2 . 3}\end{array}$ & $\begin{array}{l}5.3^{* *} \\
3.3\end{array}$ \\
\hline$(\overline{\text { GPT }})_{9}$ & $\begin{array}{l}\text { Mean } \\
\text { SD }\end{array}$ & $\begin{array}{l}4.0 * * \\
2.1\end{array}$ & $\begin{array}{l}3.6 * * \\
4.1\end{array}$ & $\begin{array}{l}5.7 * * \\
2.2\end{array}$ & $\begin{array}{l}5.6 * * \\
2.6\end{array}$ \\
\hline$(\overline{\mathrm{GPT}})_{10}$ & $\begin{array}{l}\text { Mean } \\
\text { SD }\end{array}$ & $\begin{array}{l}1.6^{* * *} \\
2.0\end{array}$ & $\begin{array}{l}3.7 * * \\
2.9\end{array}$ & $\begin{array}{l}6.0^{* *} \\
2.6\end{array}$ & $\begin{array}{l}5.2^{* *} \\
3.7\end{array}$ \\
\hline
\end{tabular}

$* *$ * denote deviations significantly different from zero; $p<.01$ and $p<.05$, respecively, with two-tailed tests.
The C "no goggles" Ptg $\mathrm{CA}_{3}, \mathrm{CA}_{4}$, and $\mathrm{CA}_{\mathrm{c}}$ effects were negative and not significant, whereas for $\mathrm{E}$ these effects were all in the predicted direction and significant. A t test comparison revealed that the $\mathrm{E}$ Ptg $\mathrm{CA}_{\mathrm{C}_{2}}$ effect was significantly larger $(2.4 \mathrm{deg})$ than that of $\mathrm{C}(\mathrm{t}=5.117$, $\mathrm{p}<.01$ ).

In the $\mathrm{C}$ groups "with goggles" test conditions, the SA test produced nonsignificant (two-tailed tests) CA effects. For E, however, there were two significant "with goggles" SA effects $\left(\mathrm{CA}_{1}\right.$ and $\left.\mathrm{CA}_{\mathrm{c}}\right)$. The difference between the $E$ and $C \mathbf{C A}_{c_{1}}$ effects 1.2 deg was not significant $(t=0.896$, $\mathrm{p}<.3$ ).

In the "no goggles" test conditions, neither $\mathbf{E}$ nor $\mathbf{C}$ produced a significant $\mathrm{CA}$ effect on the SA test. The results obtained with the SA test were not as expected. However, a two-way analysis of variance, with repeated measures on one factor, was carried out on the SA $\mathrm{CA}_{\mathrm{c}}$ effects. The two variables were groups (E/C) and type of test condition $(G / G)$. The test revealed a significant effect for type of test condition $[F(1,28)=4.60, p<.05]$ and nonsignificant effects for groups $[F(1,28)=0.47, p>.05]$ and interaction $[F(1,28)=0.79, p>.05]$. Thus, significantly more SA $\mathbf{C A}_{c}$ effect was obtained with the tone as CS when the goggles were worn (G) than when they were not worn ( $G$ ). For the $G$ conditions, the overall combined $\mathrm{E}$ and $\mathrm{C}$ mean $\mathrm{SA} \mathrm{CA}_{\mathrm{c}}$ effect $(1.8 \mathrm{deg})$ was significantly different from zero $[\mathrm{t}(29)=2.97$, $p<.01$, two-tailed test). However, the overall mean SA $\mathbf{C A}_{c}$ effect in the $\bar{G}$ conditions $(0.3 \mathrm{deg})$ was not significant $[t(29)=0.59, p>.05]$.

These results indicate that the tone 
was an effective CS for the SA test when employed with the goggles but was not effective when employed alone. Since, however, the only time that the tone was presented to $S$ during training was in the presence of the goggles, this should not be surprising. It simply implies that the conditioned effects to the tone underlying the SA test are less generalized and more specific to the exact training conditions which produced them than those underlying the Ptg test. The difficulty is the relative weakness of the alternation procedure for the SA test. Why alternation training was effective, relative to continuous training, for the SA test when the conditioning was to goggles as CS (Kravitz, 1971), and not effective when the conditioning was to a tone as CS, poses a problem presently unresolved.

In summary, all the E Ptg CA effects (both, "with goggles" and "no goggles") were significant. They were also greater than those of $C$. On the SA test, $E$ produced only two significant CA effects, both in the wG test conditions, but these were not significantly larger than those of C. C produced nonsignificant CA effects on both tests. However, the combined $E$ and $C$ CA effects revealed that the tone was an effective CS for the SA test only when employed with the goggles.

Thus, for $E$, the amount of adaptation exhibited at Ptg aftereffects was directly controlled by the tone; the amount of aftereffects measured did increase with the introduction of the tone (CA, effect), and then decreased when it was removed ( $\mathrm{CA}_{2}$ effects). Even when the tone was employed in complete isolation $(\bar{G})$, it was an effective $C S$ ( $\mathrm{CA}_{3}$ and $\mathrm{CA}_{4}$ effects).

It is clear that this finding is particularly contrary to predictions based upon a "conscious correction" hypothesis regarding $\mathrm{Ptg} \mathrm{CA}$ effects (Kravitz, 1972). If the Ss were "consciously correcting" for the presence of a prism, then one would expect that they would do so only when the testing conditions provided some possibility that a prism could be present, i.e., only in the "with goggles" testing conditions. But CA effects were also obtained in testing conditions that lacked any possibility of prism viewing, let alone of differential prismatic viewing. This confirms the verbal testimony of the Ss to the effect that they did not consciously correct for the prism during testing. We can therefore conclude that Ptg CA effects are not due to "concious correction" by $S$, and, furthermore, that the $\mathrm{E}$ Ptg CA effects are the result of a differential conditioned association between adaptation to prismatic displacement and an extrinsic CS, a tone.

\section{REFERENCES}

HARRIS, C. S. Adaptation to displaced vision: Visual, motor or proprioceptive change? Science, 1963, 140, 812-813.

KRAVITZ, J. H. Conditioned adaptation to prismatic displacement. Perception \& Psychophysics, 1972, 11, 38-42.

KRAVITZ, J. H., \& WALLACH, H Adaptation to displaced vision contingent upon vibrating stimulation. Psychonomic Science, 1966, 3, 465-469.

ROCK, I. The nature of perceptual adaptation. New York: Basic Books, 1966.

TAYLOR, J. G. The behavioral basis of perception. New Haven, Conn: Yale University Press, 1962.

WALLACH, H., KRAVITZ, J. H., \& LINDAUER, J. A passive condition for rapid adaptation to displaced visual direction. American Journal of Psy chology, 1963, 76, 568-578.

$$
\text { NOTE }
$$

1. The Ss were not instructed to close their eyes when the prism changed position, but invariably they blinked involuntarily when it did.

(Accepted for publication May 17, 1972.) 